\title{
Controlling shell-side crystal nucleation in a gas-liquid membrane contactor for simultaneous ammonium bicarbonate recovery and biogas upgrading
}

\author{
A. McLeod, P. Buzatu, O. Autin, B. Jefferson and E. McAdam* \\ Cranfield Water Science Institute, Building 39, Cranfield University, Bedfordshire, MK43 OAL, UK \\ *Corresponding author e-mail: e.mcadam@cranfield.ac.uk
}

\section{Abstract}

A gas-liquid hollow fibre membrane contactor (HFMC) process has been introduced for carbon dioxide $\left(\mathrm{CO}_{2}\right)$ separation from biogas where aqueous ammonia $\left(\mathrm{NH}_{3}\right)$ is used to chemically enhance $\mathrm{CO}_{2}$ absorption and initiate heterogeneous nucleation of the reaction product ammonium bicarbonate at the membrane-solvent interface. Aqueous ammonia absorbents ( 2 to $7 \mathrm{M}$ ) were initially used in single pass for $\mathrm{CO}_{2}$ separation from a synthetic biogas where nucleation of ammonium bicarbonate crystals was observed at the perimeter of the micropores. Recirculation of the aqueous ammonia absorbent encouraged the growth of ammonium bicarbonate crystals on the shell-side of the membrane that measured several microns in diameter. However, at high aqueous $\mathrm{NH}_{3}$ concentrations (3-7 M), lumen side crystallisation occurred and obstructed gas flow through the lumen of the HFMC. The suggested mechanism for lumen-side crystallisation was absorbent breakthrough into the lumen due to pore wetting which was promoted by low absorbent surface tension at high $\mathrm{NH}_{3}$ concentration. Preferential shell-side nucleation can therefore be promoted by: (1) raising surface tension of the absorbent; and, (2) selection of a membrane with a more regulated pore shape than the PTFE membrane used $(d / L$ 0.065) as both actions can diminish solvent ingress into the pore. This was evidenced using $2 \mathrm{M} \mathrm{NH}_{3}$ absorbent where shell-side crystallisation was evidenced without the onset of lumen side crystallisation. Raising surface tension through the inclusion of salt into the chemical absorbent also promoted greater $\mathrm{CO}_{2}$ flux stability. Importantly, this study demonstrates that chemically enhanced HFMC are an attractive prospect for gas-liquid separation applications where reaction product recovery offers further economic value.

Keywords: biomethane, membrane crystalliser, chemical absorption, crystallisation

Published by Elsevier. This is the Author Accepted M anuscript issued with:

Creative Commons Attribution Non-Commercial No Derivatives License (CC:BY:NC:ND 3.0). 


\section{Introduction}

Many water utilities are now refining biogas into biomethane rather than using directly for electrical production due to the potential for higher revenue. To illustrate, in the UK, through support under the Renewable Heat Incentive (RHI), the revenue expected from biomethane is $€ 0.39 \mathrm{~m}^{-3}$ which compares to only $€ 0.23 \mathrm{~m}^{-3}$ for electrical production (Read et al., 2010). The biomethane product must achieve methane quality that is equivalent or higher than natural gas $(>81 \%)$ which therefore demands the separation of carbon dioxide $\left(\mathrm{CO}_{2}\right)$ from biogas. This is generally facilitated using absorption in a packed column and is analogous to those currently trialled for carbon capture and storage (CCS). In CCS applications, process intensification is provided through the inclusion of a chemical solvent (e.g. monoethanolamine) that reacts with $\mathrm{CO}_{2}$ to enhance the separation. However, the energy demanded for chemical solvent regeneration, coupled with solvent losses (due to volatility and degradation pathways) and the demand for specialist operators has limited uptake of chemical absorption for biogas upgrading by water utilities (Heile et al., 2014).

Ammonia is now recognised as an emerging chemical absorbent in CCS due to its higher absorption efficiency, greater chemical stability and lower energy demand for regeneration (Shuangchen et al., 2013; Makhloufi et al., 2014). Aqueous ammonia $\left(\mathrm{NH}_{3}\right)$ absorption therefore presents comparable advantages for water utilities undertaking biogas upgrading, but also offers the unique opportunity to utilise the ammonia rich wastewater produced onsite as a low cost absorbent feedstock for enhanced $\mathrm{CO}_{2}$ separation. The reaction between free $\mathrm{NH}_{3}$ and $\mathrm{CO}_{2}$ is known to proceed by (Eq. 1) where ammonium bicarbonate $\left(\mathrm{NH}_{4} \mathrm{HCO}_{3}\right)$ is the reaction product formed:

$$
\mathrm{CO}_{2}+\mathrm{NH}_{3}+\mathrm{H}_{2} \mathrm{O} \rightarrow\left(\mathrm{NH}_{4}\right) \mathrm{HCO}_{3}
$$

When recovered in crystalline form, $\mathrm{NH}_{4} \mathrm{HCO}_{3}$ can be used as an ammonia rich fertiliser as well as a feedstock in commercial manufacture. Consequently, controlled production of a crystalline $\mathrm{NH}_{4} \mathrm{HCO}_{3}$ reaction product from ammonia rich wastewaters posits several advantages for biogas upgrading at sewage works including: further reduction in energy demand for absorbent regeneration; a 
reduction in load onto nitrification/denitrification processes $\left(€ 3 \mathrm{kgN}^{-1}\right)$; and, production of $\mathrm{NH}_{4} \mathrm{HCO}_{3}$ as a new revenue stream (bulk cost $€ 111$ tonne $^{-1}$ ) (Thornton, 2007).

To enable recovery of crystalline products within a controlled environment, Curcio et al. (2001) introduced the membrane crystallisation reactor (MCr). In their work, a microporous hydrophobic membrane contactor (HFMC) was used to facilitate non-dispersive contact between a heated undersaturated crystallising solution (on the retentate side) and cooled pure water on the permeate side. The temperature differential provided the gradient for vapour transport from the crystallising solution through the membrane pores enabling an increased solute concentration (sodium chloride, $\mathrm{NaCl}$ ) which upon exceeding its solubility limit, initiated nucleation and growth of $\mathrm{NaCl}$ crystals (Figure 1). The underpinning mechanism by which the $\mathrm{MCr}$ operates therefore corresponds to evaporation-migration-condensation (Di Profio et al., 2010) and has been used to recover $\mathrm{NaCl}$ and magnesium sulfate from nanofiltration retentate as crystalline products (Drioli et al., 2004) and for the controlled production of Lysozyme crystals (Di Profio et al., 2003).

The same microporous HFMC technology used to control crystallisation in MCr systems has now also been used to enable $\mathrm{CO}_{2}$ separation from biogas through supporting an analogous absorption mechanism to conventional absorption columns (Heile et al., 2014). In this case, the hydrophobic membrane facilitates non-dispersive contact between the chemical absorbent and gas phase with the gases free to diffuse through the open pore structure. Due to the increase in specific surface area afforded by the membrane contactor, the technology presents an inherent advantage in reducing both process scale and absorption solvent consumption, relative to conventional columns (Herzog and Pederson, 2000). In this study, we therefore seek to introduce a gas-liquid membrane absorption crystallisation reactor that enables both the selective separation of $\mathrm{CO}_{2}$ through reaction with ammonia and the subsequent nucleation and growth of the crystalline ammonium bicarbonate reaction product for recovery. The mechanism for nucleation and growth of $\mathrm{NH}_{4} \mathrm{HCO}_{3}$ crystals in this study differs from classical $\mathrm{MCr}$ systems in that supersaturation is achieved by counter diffusion of solutes through the transport of $\mathrm{CO}_{2}$ molecules from the gas phase into the 
crystallising fluid (an aqueous ammonia absorbent) where the driving force for $\mathrm{CO}_{2}$ transport to the crystallising fluid is the enhancement in solubility provided by the chemical reaction with $\mathrm{NH}_{3}$. Nucleation is then dependent upon $\mathrm{CO}_{2}$ reaching sufficient concentration to initiate local supersaturation of the solvent (Figure 1).

Makhloufi et al. (2014) recently screened a number of hollow-fibre membrane materials to determine compatibility for $\mathrm{CO}_{2}$ absorption into aqueous ammonia for chemically enhanced post combustion CCS. The authors remit precluded an interest in recovering $\mathrm{NH}_{4} \mathrm{HCO}_{3}$ as a byproduct and determined that microporous fibres were inappropriate for application to $\mathrm{CCS}$ due to $\mathrm{CO}_{2}$ flux instability caused by ammonium bicarbonate precipitation on the gas-side (lumen-side) of the membrane. In this study, we therefore seek to introduce the mechanism underpinning controlled nucleation and growth of ammonium bicarbonate on the shell-side (absorbent side) of a microporous HFMC to illustrate the potential of the gas-liquid membrane absorption crystallisation reactor for simultaneous gas separation with reaction product recovery. A microporous polytetrafluoroethylene (PTFE) HFMC is therefore used to investigate: (i) the potential for chemical absorption in a microporous membrane to enable shell-side (absorbent side) crystal nucleation; (ii) investigation of absorbent conditions required to enable crystal growth; and (iii) the role of the microporous substrate in controlling nucleation. To our knowledge, this is the first study to describe the use of hydrophobic microporous membranes for the controlled nucleation and growth of a reactant product following chemical absorption from the gas phase.

\section{Experimental}

\subsection{Fabrication, setup and operation of equipment}

Hydrophobic micro-porous PTFE fibres obtained from Markel Corporation (Plymouth Meeting, Pennsylvania, USA) and comprised a $200 \mu \mathrm{m}$ wall thickness and $44 \%$ porosity (Table 1 ). To enable characterisation of crystal growth with minimal disturbance, single fibre modules were manufactured. Modules comprised a transparent PVC shell with an inner diameter of $0.004 \mathrm{~m}$ and 
were completed with two acetal push-fit T-union-joints (1/4" Speedfit, John Guest Ltd., Middlesex, UK). Fibres were potted in epoxy resin (Bostik Ltd., Stafford, UK). For dense membrane experiments, polydimethylsiloxane (PDMS) fibres with a wall thickness of $65 \mu \mathrm{m}$ were used in an identical module construction (Trelleborg sealing solutions, Stuttgart, Germany). Methane $\left(\mathrm{CH}_{4}, 99.995 \%\right)$ and carbon dioxide $\left(\mathrm{CO}_{2}, 99.7 \%\right)$ (BOC gases, Ipswich, UK) were mixed in controlled proportions using mass flow controllers $\left(0.2-20.01 \mathrm{~min}^{-1}\right.$, Roxspur Measurement and Control Ltd., Sheffield, UK) to provide an initial $50: 50 \mathrm{CH}_{4}: \mathrm{CO}_{2}$ gas composition and introduced through the fibre lumen (Figure 2). Liquid was pumped co-currently into the shell-side. Transmembrane pressure (TMP) was monitored by digital pressure gauges (DPG1000, Omega Engineering Ltd., Manchester, UK) and liquid and pressure flow controlled using needle valves.

\subsection{Sampling and analyses}

119 Ammonia absorbents were prepared through dilution of an $\mathrm{NH}_{3}$ concentrate (35\%, Fisher Chemicals, Loughborough, UK) using de-ionised (DI) water $\left(15.0 \mathrm{M} \Omega \mathrm{cm}^{-1}\right)$. Absorbent $\mathrm{pH}$ was fixed to $\mathrm{pH} 11$ to ensure $100 \%$ of the ammoniacal nitrogen was available as un-ionised free $\mathrm{NH}_{3}$ (Thurston et al., 1979). Ammonia concentrations were confirmed by use of an ammonium cell test $\left(4-80 \mathrm{mg} \mathrm{I}^{-1}\right.$, VWR International Ltd., Poole, UK) with subsequent determination by spectrophotometry (Spectroquant Nova 60, Merck-Millipore, Darnstadt, Germany). Gas composition was determined using an infrared biogas analyser sited on the gas outlet (range $0-100 \%$, accuracy $<0.2 \%$ full-scale; Yieldmaster, Bluesens gas sensor $\mathrm{GmbH}$, Herten, Germany). Subsequently, $\mathrm{CO}_{2}$ removal efficiency was determined based upon the binary gas composition before and after the membrane module:

$\mathrm{CO}_{2}$ removal efficiency $(\%)=\frac{\left(c_{G, \text { in }}-c_{G, o u t}\right)}{c_{G, \text { in }}} \times 100$ where $\mathrm{C}_{\mathrm{G}}$, in and $\mathrm{C}_{\mathrm{G} \text {, out }}$ are gas phase $\mathrm{CO}_{2}$ concentrations before and after the $\mathrm{HFMC}$ respectively (mol $\mathrm{mol}^{-1}$ ). Gas flow rate exiting the contactor was measured using a bubble flow meter (50 ml, Restek, Bellefonte, US) and used to calculate carbon dioxide flux $\left(\mathrm{J}_{\mathrm{CO} 2}, \mathrm{~mol} \mathrm{~m}^{-2} \mathrm{~s}^{-1}\right)$ : 
133 where $Q_{G}$, in and $Q_{G}$, out are gas flow rate before and after HFMC respectively $\left(m^{3} s^{-1}\right), A_{m}$ is the membrane surface area for absorption $\left(\mathrm{m}^{2}\right)$ and $\mathrm{T}_{\mathrm{G}}$ is the gas temperature (K) (Atchariyawut et al., 2007). scanning electron microscope (SEM) equipped with a field emission gun (sFEG) (XL30, FEI, Hillsboro, Oregon, USA). Pores size data was subsequently analysed to provide a size distribution using a lognormal distribution function (Li et al., 2000):

$f_{L}(r)=\frac{1}{\sqrt{2 \pi r}}\left[\ln \left(1+\sigma^{2}\right)\right]^{-0.5} \times \exp \left[-\frac{\left(\ln \left(r / r_{m}\right)\left(1+\sigma^{2}\right)^{0.5}\right)^{2}}{2 \times \ln \left(1+\sigma^{2}\right)}\right]$

141 Surface roughness of the virgin fibres was characterised using atomic force microscopy (AFM, Dimension 3100, Bruker, Massachusetts, US). Examination of sacrificial membrane samples to determine crystal nucleation and growth was conducted using SEM (upto x10000 magnification) for the finer diameter PTFE fibres, and optical microscope for the wider diameter PDMS fibres. Fibre samples for SEM were first coated with gold-palladium (Au-Pd) using a cool sputtering SEM coating unit (E5100, Polaron Equipment/Quorum Technologies Ltd., Lewes, UK). Spectroscopic elemental analysis was performed in tandem with SEM by energy dispersive x-ray spectroscopy (EDX) using Aztec software (Oxford Instruments NTS, Abingdon, UK). Solvent surface tension was determined using a Du Noüy ring tensiometer (Kruss K6, Bristol, UK).

\section{Results}

\subsection{Characterisation of the PTFE and PDMS membranes}

Pore size analysis by SEM indicated that average pore radius of the PTFE fibres was $0.157 \mu \mathrm{m}$ with radii distributed within a range between $0.13 \mu \mathrm{m}$ and $0.21 \mu \mathrm{m}$ (Figure 3). This closely approximates to pore width data provided by the manufacturer (Table 1). The stretched length of the pores was approximately $4.9 \pm 3.1 \mu \mathrm{m}$, yielding a pore diameter to length ratio $(d / L)$ of 0.065 . Average surface 
roughness of the PTFE fibres was $82 \mathrm{~nm}$ which is similar to that measured for the nonporous PDMS membrane $(77 \mathrm{~nm})$.

\subsection{Removal of $\mathrm{CO}_{2}$ using $\mathrm{NH}_{3}$ as a chemical absorbent}

161

162

163

The PTFE HFMC was initially tested in single pass mode (without absorbent recirculation). Gas velocity, $V_{G}$, was varied between $0.28 \mathrm{~m} \mathrm{~s}^{-1}$ and $18.62 \mathrm{~m} \mathrm{~s}^{-1}$ whilst both liquid velocity $\left(\mathrm{V}_{\mathrm{L}}\right)$ and aqueous ammonia absorbent concentration were fixed at $0.02 \mathrm{~m} \mathrm{~s}^{-1}$ and $7 \mathrm{~mol} \mathrm{I}^{-1}$ respectively (Figure 4). Maximum $\mathrm{CO}_{2}$ removal efficiency of $72 \%$ was observed at the lowest $\mathrm{V}_{\mathrm{G}}$ examined which corresponded to a G/L ratio of 3. For these fixed conditions, methane content increased from $50 \%$ at the inlet to $86 \% \mathrm{CH}_{4}$. As $\mathrm{V}_{\mathrm{G}}$ was increased, $\mathrm{CO}_{2}$ removal efficiency decreased to a minimum of $3.6 \%$ which was recorded at the highest $\mathrm{V}_{\mathrm{G}}$ tested $\left(18.62 \mathrm{~m} \mathrm{~s}^{-1}\right)$. Whilst $\mathrm{CO}_{2}$ removal efficiency declined with an increase in $\mathrm{V}_{\mathrm{G}}, \mathrm{CO}_{2}$ flux increased from 0.015 to $0.116 \mathrm{~mol} \mathrm{~m}^{-2} \mathrm{~s}^{-1}$ within the gas velocity range tested (Figure 4). Microscopic analysis of the shell-side of a PTFE fibre that had been used with $7 \mathrm{~mol} \mathrm{I}^{-1}$ aqueous ammonia solution and a G/L ratio of 10 , showed white specks formed around the pore mouths indicating that crystal nucleation had been initiated (Figure 5).

\subsection{Identification of heterogeneous crystal growth}

Crystal growth on the shell side of the module was identified within each of the 2 to $5 \mathrm{M} \mathrm{NH}_{3}$ absorbents used $\left(V_{G}=0.93 \mathrm{~m} \mathrm{~s}^{-1}, \mathrm{G} / \mathrm{L} 10\right)$ with carbon $(\mathrm{C})$, oxygen $(\mathrm{O})$ and nitrogen $(\mathrm{N})$ peaks confirmed in the crystals formed by EDX (Table 2). Crystals that had grown in 3 to $5 \mathrm{molNH}_{3} \mathrm{I}^{-1}$ absorbents generally developed planar structures that were oriented roughly parallel to the membrane surface with multiple points of contact, whereas those formed in the 2 molNH $_{3} \mathrm{I}^{-1}$ absorbent developed perpendicular to the membrane surface with fewer crystal-membrane contact points. Following two to five absorbent recirculations (five second residence time per recirculation in the PTFE HFMC), a progressive decline in $\mathrm{CO}_{2}$ flux was observed at each free ammonia concentration tested (Figure 6). After 6 and 13 recirculations respectively (30 s to $65 \mathrm{~s}$ ), the 3 and $5 \mathrm{~mol} \mathrm{I}^{-1} \mathrm{NH}_{3}$ 
absorbent experiments were stopped due to lumen-side crystallisation which blocked the flow of gas

(Figure 7). Lumen side crystals were tightly packed and propagated along the length of the hollow fibre. A similar progressive decline in $\mathrm{CO}_{2}$ flux was also observed using $2 \mathrm{molNH}_{3} \mathrm{I}^{-1}$ absorbent. However, whilst shell-side crystallisation was evidenced in the $2 \mathrm{molNH}_{3} \mathrm{I}^{-1}$ absorbent (Table 2), lumen-side crystallisation was not observed following 34 absorbent recirculations (170 s).

\subsection{Using membrane type to control lumen-side crystallisation}

Performance of a nonporous PDMS membrane (Figure 8) was compared to the microporous membrane performance by recirculating 5 molNH$_{3} \mathrm{I}^{-1}$ absorbent and fixing hydrodynamic conditions sufficient to yield equivalent $\mathrm{CO}_{2}$ fluxes to the PTFE membrane (G/L 0.39, Figure 8). Under these conditions the $\mathrm{NH}_{3}$ solvent had a $1 \mathrm{~s}$ residence time within the PDMS HFMC. A steady state period was observed between 400 and 800 solvent recirculations, which corresponded to $\mathrm{CO}_{2}$ fluxes of around $0.014 \mathrm{~mol} \mathrm{~m}^{-2} \mathrm{~s}^{-1}$. However, after around 800 recirculations a progressive decline in $\mathrm{CO}_{2}$ flux was noted and the experiment was terminated after 931 recirculations. Whilst crystals were observed to have grown on the shell-side of the PDMS fibre (Figure 9), the reduction in $\mathrm{CO}_{2}$ flux after 800 recirculations coincided with the formation of crystalline solid within the fibre lumen inducing deformation of the cylindrical fibre structure.

200

\subsection{Manipulating solvent chemistry to promote shell-side nucleation on PTFE fibres}

202

Carbon dioxide flux provided by the PTFE membrane using 3 molNH$_{3} \mathrm{I}^{-1}$ absorbent during recirculation were compared when using $1 \%$ wt. glycerol as an additive to the $3 \mathrm{molNH}_{3} \mathrm{I}^{-1}$ absorbent as the addition of glycerol has been shown to diminish the volatility of ammonia (Shuangchen et al., 2013)(Figure 10). With the glycerol added, initial mean $\mathrm{CO}_{2}$ flux was $3.5 \%$ lower than without glycerol addition and after 12 recirculations, $\mathrm{CO}_{2}$ flux was $23 \%$ lower than with the pure 3 molNH$\left._{3}\right|^{-1}$ absorbent. Conversely, the addition of $5 \%$ wt. NaCl to the 3 molNH$\left.\right|_{3}{ }^{-1}$ absorbent increased $\mathrm{CO}_{2}$ flux 
stability. To illustrate, after 13 recirculations of the $3 \mathrm{molNH}_{3} \mathrm{I}^{-1}$ absorbent with $5 \% \mathrm{wt}$. $\mathrm{NaCl}$ added, $\mathrm{CO}_{2}$ flux was $91 \%$ of initial flux in comparison to only $81 \%$ for the $3 \mathrm{molNH}_{3} \mathrm{I}^{-1}$ absorbent. The change in surface tension following an increase in $\mathrm{NaCl}$ or aqueous ammonia concentration to deionised water was studied (Figure 11). With the inclusion of between 0.1 and 1 $\mathrm{M} \mathrm{NaCl}$ (5.85\% wt.), surface tension increased by up to $2.2 \mathrm{mN} \mathrm{m}^{-1}$. However, a reduction in surface tension of between -0.8 and $-8.7 \mathrm{mN} \mathrm{m}^{-1}$ was measured for concentrations between 0.3 and 7 molNH${ }_{3} I^{-1}$ which is within the range of aqueous ammonia absorbents studied and is consistent with the literature (Weissenborn et al., 1995). The addition of $5 \% \mathrm{wt}$. $\mathrm{NaCl}$ to aqueous ammonia reduced the change in surface tension. For example, at a concentration of $\left.3 \mathrm{molNH}_{3}\right|^{-1}$ a reduction in surface tension of $-6.7 \mathrm{mN} \mathrm{m}^{-1}$ was recorded whereas with the inclusion of $5 \% \mathrm{wt} . \mathrm{NaCl}$, the change in surface tension reduced to only $-3.9 \mathrm{mN} \mathrm{m}^{-1}$.

\section{Discussion}

In this study, the use of a liquid phase chemical reaction to enhance $\mathrm{CO}_{2}$ absorption and produce a crystalline reaction product has been demonstrated using a PTFE microporous hydrophobic hollow fibre membrane to promote the nucleation and growth of ammonium bicarbonate. During single pass experiments using a $7 \mathrm{~mol} \mathrm{I}^{-1}$ ammonia absorbent, an increase in $\mathrm{V}_{\mathrm{G}}$ increased $\mathrm{CO}_{2}$ flux into the receiving ammonia absorbent. In chemically reactive absorption systems, an increased gas phase flow rate is often observed to mediate solute flux (Esquiroz-Molina et al., 2013) as this enables replenishment of $\mathrm{CO}_{2}$ at the solvent-membrane interface and maintenance of a high bulk gas $\mathrm{CO}_{2}$ partial pressure (Zeng et al., 2013). When operating at high $V_{G}(G / L ~ 10)$ using $7 \mathrm{~mol} \mathrm{I}^{-1}$ ammonia absorbent $\left(\mathrm{CO}_{2}\right.$ flux $0.116 \mathrm{~mol} \mathrm{~m}^{-2} \mathrm{~s}^{-1}$, Figure 4$)$, an absorption rate of $44.2 \mathrm{kmol} \mathrm{m}^{-3} \mathrm{~h}^{-1}$ was recorded $\left(\mathrm{kmolCO}_{2} \mathrm{~m}^{-3}\right.$ absorption reactor volume $\left.\mathrm{h}^{-1}\right)$. For comparison, Zeng et al. (2013) recorded a $\mathrm{CO}_{2}$ absorption rate of $3.3 \mathrm{kmol} \mathrm{m}^{-3} \mathrm{~h}^{-1}$ in a packed column using aqueous ammonia $\left(4.5 \mathrm{~mol} \mathrm{I}^{-1}\right)$, which illustrates the high rate of $\mathrm{CO}_{2}$ transfer achieved with the micro-porous HFMC. For this high flux condition, activation of a substantial number of nucleation sites around the micro-pores on the 
shell-side of the PTFE was demonstrated (Figure 5). This is supported by the work of Di Profio et al. (2003) where increased solute concentration enhanced supersaturation leading to an excess of nucleation. Interestingly, crystallisation is generally not observed in $\mathrm{CO}_{2}$ /aqueous ammonia packed columns unless the ammonia concentration exceeds around $6 \mathrm{~mol} \mathrm{I}^{-1}$ (Budzianowski et al., 2011). In this study, nucleation and crystal growth was observed at $2 \mathrm{~mol}^{-1}$ (Table 2). The enhanced nucleation potential of the hydrophobic PTFE membrane can be explained by the high contact angle exhibited (around $129^{\circ}$ for PTFE-water: Guillen-Burrieza et al., 2013; Zhu et al., 2013) which favours heterogeneous nucleation over homogeneous nucleation (Figure 12). The contact angle reflects the three phase line at the perimeter of the pore mouth, where the $\mathrm{CO}_{2}$ gas phase, aqueous ammonia phase and PTFE solid phase interact (Figure 1; Curcio et al., 2006) and accounts for the proximity of nucleation sites relative to the pore mouth. The inclusion of pores reduces the thermodynamic preference for heterogeneous nucleation, although this is compensated for by the selection of a more hydrophobic material. Additionally, the provision of specific sites for nucleation at three phase line around the pore mouths, materials with increased porosity show an enhanced rate of nucleation, offering a kinetic preference for nucleation upon the membrane that complements the stability due to high contact angle (Curcio et al., 2006). It is proposed that the nucleation mechanism is analogous to that underpinning evaporation-migration-condensation as seen in $\mathrm{MCr}$ which is thought to follow: (1) surface adsorption through non-specific attractive interaction; (2) hindrance of lateral migration by the irregular pore structure causing packing; and (3) molecular entrapment which induces relatively higher supersaturation (Di Profio et al., 2010). However, within the gas crystallisation process proposed, $\mathrm{CO}_{2}$ will migrate from the gas phase through the stagnant region of the solvent meniscus resident within the pore to the nucleation site, the rate of which will be determined by the reactivity of the solvent.

Growth of ammonium bicarbonate crystals on the shell-side of the membrane was demonstrated following recirculation of the ammonia absorbent (Table 2). Crystals grown within 3 and $5 \mathrm{molNH}_{3} \mathrm{I}^{-1}$ absorbents differed from those grown within $\left.2 \mathrm{molNH}_{3}\right|^{-1}$ absorbent which were 
characterised by growth perpendicular to the membrane surface and from a comparatively limited number of nucleation points. Lowering the aqueous ammonia concentration to $2 \mathrm{molNH}_{3} \mathrm{I}^{-1}$ results in two effects: (1) this is close to the nominal limiting saturation concentration for the reactant product $\left(\mathrm{NH}_{4} \mathrm{HCO}_{3}, 2.24\right.$ mol I-1); and (2) the flux of $\mathrm{CO}_{2}$ into the aqueous phase is reduced due to the lower absorbent reactivity. The crystal orientation identified at low fluxes is indicative of conditions favouring crystal growth over nucleation, and is analogous to observations made previously when employing low solvent fluxes for evaporative MCr (Zhang et al., 2008) which results in production of fewer larger crystals. Controlling preference for the growth of fewer, larger crystals perpendicular to the membrane surface may be key to harvesting of the $\mathrm{NH}_{4} \mathrm{HCO}_{3}$ product, where it has been indicated that shear stresses due to axial liquid flow are sufficient to detach crystals grown upon the hydrophobic surface (Di Profio et al., 2010).

Following extensive solvent recirculation, crystal growth was observed on the lumen side of the PTFE fibre (Figure 7). In a preliminary evaluation of $\mathrm{CO}_{2}$ absorption into aqueous $\mathrm{NH}_{3}$ using oxyphan ${ }^{\circledast}$ microporous hollow fibres, Makhloufi et al. (2014) postulated that the $\mathrm{CO}_{2}$ flux decline observed was due to lumen-side (gas-side) crystallisation which initiated through high ammonia slip into the humidified gas phase. To investigate this mechanism, in this study, glycerol (1\%) was added to the aqueous ammonia absorbent used with the microporous PTFE membranes as this is commonly employed to suppress $\mathrm{NH}_{3}$ volatility by the glycerol hydroxyl group bonding to the free ammonia (Shuangchen et al., 2013). However, with the inclusion of glycerol, $\mathrm{CO}_{2}$ flux declined more rapidly than without glycerol addition suggesting that glycerol-ammonia bonding also retarded mass transfer (Cheng et al., 2003). Direct measurement of ammonia slip could not be made in this study due to scale. However, ammonia slip has been measured by this group using a larger contactor scale $\left(0.79 \mathrm{~m}^{2}\right)$ and similar process conditions $\left(5 \mathrm{~mol} \mathrm{I}^{-1}\right.$ aq. $\left.\mathrm{NH}_{3} ; \mathrm{G} / \mathrm{L} 7.5\right)$ and a slip of only $0.015 \% \mathrm{NH}_{3}$ noted which is ostensibly insufficient to grow the crystal mass observed within the fibre. The low slip can be explained by the low liquid velocities imposed, for which the depletion of ammonia through reaction with $\mathrm{CO}_{2}$ extends radially away from the fibre wall toward the bulk (Figure 13). This is 
experimentally corroborated at high $\mathrm{G} / \mathrm{L}$ ratios where high $\mathrm{CO}_{2}$ fluxes are coincident with diminished $\mathrm{CO}_{2}$ removal efficiency (Figure 4) due to the decrease in mole ratio between $\mathrm{NH}_{3}$ and $\mathrm{CO}_{2}$ in the reaction zone (Zeng et al., 2013). At a G/L of 3, the methane content in the outlet gas exceeding the $\mathrm{CH}_{4}$ content of North Sea natural gas (Persson et al., 2007) which indicated that the gas treatment objective can be met whilst limiting the free ammonia concentration (and hence slip) at the gasliquid interface.

Higher aqueous ammonia concentrations were demonstrated to lower absorbent surface tension considerably (Figure 11). Lower surface tension is known to decrease breakthrough pressure for a cylindrical pore (Franken et al., 1987) which notably enhances the probability for wetting:

$\Delta P_{B . P .}=\frac{-4 B \sigma \cos \theta}{d_{\max }}$

It is suggested that the reduction in surface tension observed at high aqueous ammonia concentration enables penetration of the ammonia rich absorbent into the pore and into the $\mathrm{CO}_{2}$ rich gas phase initiating crystal nucleation in the lumen side of the microporous membrane. This was evidenced by the faster onset of lumen-side (gas-phase) crystal growth within aqueous ammonia concentrations greater than $3 \mathrm{M}$, which were characterised by a relatively large reduction in surface tension ( $\Delta \sigma-5.6$ to $-9.6 \mathrm{mN} \mathrm{m}^{-1}$, Figure 11$)$. For comparison, whilst shell-side crystallisation was noted within the lower concentration $2 \mathrm{molNH}_{3} \mathrm{I}^{-1}$ absorbent, lumen-side crystal growth was absent. However, the progressive and gradual decline in $\mathrm{CO}_{2}$ flux noted for the $2 \mathrm{molNH}_{3} \mathrm{I}^{-1}$ absorbent remains indicative of progressive pore wetting (Bougie et al., 2013); it is therefore asserted that the lower surface tension change measured at $2 \mathrm{molNH}_{3} \mathrm{I}^{-1}$ was insufficient to enable complete breakthrough into the lumen side. The role of surface tension in inhibiting both lumen-side crystallisation and wetting was confirmed through the addition of $5 \%$ wt. sodium chloride which counteracted the transition in surface tension introduced by the aqueous ammonia. Whilst the inclusion of $\mathrm{NaCl}$ increased surface tension of the aqueous ammonia by only $2.8 \mathrm{mN} \mathrm{m}^{-1}$, a marked increase in $\mathrm{CO}_{2}$ flux stability was observed (Figure 10, Figure 11). 

side crystallisation observed with microporous membranes at high aqueous concentrations, as they increase resistance to absorbent breakthrough whilst also being hydrophobic (contact angle with water approximately $110^{\circ}$ : Aerts et al., 2006; Jadav et al., 2012). Whilst some crystal growth was observed on the shell-side of the PDMS membrane, crystal growth predominated on the lumen-side of the membrane within the gas phase (Figure 9). To generate analogous flux rates to those of the PTFE membrane, a high liquid velocity was used (G/L 0.39) which enhances surface renewal of free ammonia at the absorbent-membrane boundary and hence the potential for ammonia slip. Furthermore, since ammonia is a smaller and more condensable molecule than $\mathrm{CO}_{2}$, it is more permeable through PDMS (Makhloufi et al., 2014). Consequently co-permeability of both free ammonia and water vapour in the dense PDMS membrane promoted crystal growth within the fibre lumen and within the dynamic free volume network of the rubbery PDMS membrane which induced fibre wall distortion. Wetting and subsequent lumen-side crystallisation can be ascribed to the stretched pore shape of the microporous membrane in this study in addition to the surface tension of the absorbent. Stretched pores are a common feature of several commercially available hydrophobic polymeric microporous membranes ( $d / L 0.48$, Heile et al., 2014 ) but was exacerbated within the PTFE fibre studied ( $d / L$ 0.065). Franken et al. (1987) introduced a pore geometry coefficient $(B)$ to the Laplace-Young equation (Eq. 5) where non-cylindrical pore shape was classified by a coefficient of between $0<B<1$. This emphasises that pore wetting in exacerbated as pore shape tends away from that of a cylinder (Bougie et al., 2013). Consequently, microporous membranes with tighter pore shape together with surface tension regulation of the solvent are recommended to encourage preferential shell-side crystallisation and enhanced $\mathrm{CO}_{2}$ flux stability in gas-liquid membrane absorption crystallisation reactors. 
The use of microporous hollow fibre membrane contactors has been introduced to enable the nucleation and growth of crystalline reaction products initiated through chemically facilitated $\mathrm{CO}_{2}$ separation from the gas phase. This represents the first membrane crystallisation reactor where the solubility limit to initiate nucleation is reached through counter diffusion of solutes from the solvent bulk to the membrane and of solutes from the 'permeate-side' through the membrane micropores into the membrane-solvent boundary. Lumen-side crystallisation can be avoided in favour of preferential shell-side nucleation and more stable $\mathrm{CO}_{2}$ fluxes by: (1) raising surface tension of the absorbent through either limiting aqueous ammonia concentration or addition of a surface tension regulator; and, (2) selection of a membrane with a more regulated pore shape than the PTFE membrane used $(d / L$ 0.065) as both actions can diminish solvent ingress into the pore. Although limiting aqueous ammonia concentration will diminish solvent reactivity and $\mathrm{CO}_{2}$ flux, which suggests a larger process scale, the value ascribed to controlled production of the reaction product must also be weighted. Further refinement is required to ensure that longer term $\mathrm{CO}_{2}$ flux stability can be ascertained simultaneously with ammonium bicarbonate growth. However, the progressive decline in $\mathrm{CO}_{2}$ flux with the lower ammonia absorbent concentration was notably a result of wetting rather than interference of shell-side crystal growth. Whilst a high initial aqueous ammonia concentration initiated a large number of nucleation sites, the absorbent ammonia concentration also influenced morphology of crystals formed on the shell-side. Crystals formed within lower absorbent ammonia concentration (and lower $\mathrm{CO}_{2}$ fluxes) possessed fewer nucleation sites and are characteristic of crystals preferentially grown under low flux conditions to favour growth over nucleation. This represents a potentially favourable characteristic for the continued detachment (and hence recovery) of the ammonium bicarbonate crystals formed, where the low shear stresses applied in continuous $\mathrm{MCr}$ have been shown sufficient to enable detachment and downstream recovery of the crystalline product (Di Profio et al., 2010). 
The authors would like to thank the Engineering and Physical Sciences Research Council (EPSRC, V/N: 08001923), Anglian Water, Northumbrian Water, Severn Trent Water and Yorkshire Water for their financial support, and Markel Corporation for their kind donation of the micro-porous PTFE hollow fibre membranes.

366

References

S. Aerts, A. Vanhulsel, A. Buekenhoudt, H. Weyten, S. Kuypers, H. Chen, M. Bryjak, L.E.M. Gevers,

F. Bougie, M.C. Lliuta, Analysis of Laplace-Young equation parameters and their influence on efficient $\mathrm{CO}_{2}$ capture in membrane contactors, Sep. Purif. Technol. 118 (2013) 806-815.

W.M. Budzianowski, Mitigating $\mathrm{NH}_{3}$ vaporisation from an aqueous ammonia process for $\mathrm{CO}_{2}$ capture, Int. J. Chem. React. Eng. 9 (2011) 1-27.

W.L. Cheng, Z.S. Chen, A. Akisawa, P. Hu, T. Kashiwangi, Theoretical and experimental study on surface tension and dynamic surface tension of aqueous lithium bromide and water with additive, Sci. China 46 (2003) 191-203.

E. Curcio, A. Criscuoli, E. Drioli, Membrane crystallizers, Ind. Eng. Chem. Res. 40 (2001) 2679-2684.

E. Curcio, E. Fontananova, G. Di Profio, E. Drioli, Influence of the structural properties of poly(vinylidene fluoride) membranes on the heterogeneous nucleation rate of protein crystals, J. Phys. Chem. B 110 (2006) 12438-12445.

P.W.J. Derks, G.F. Versteeg, Kinetics of absorption of carbon dioxide in aqueous ammonia solutions, Energ. Proc. 1 (2009) 1139-1146. 

crystallizers: Facts and perspectives, Ind. Eng. Chem. Res. 49 (2010) 11878-11889.

G. Di Profio, E. Curcio, A. Cassetta, D. Lambda, E. Drioli, Membrane crystallisation of lysozyme: kinetic aspects, J. Cryst. Growth 257 (2003) 359-369.

A. Esquiroz-Molina, S. Georgaki, R. Stuetz, B. Jefferson, E.J. McAdam, Influence of pH on gas phase controlled mass transfer in a membrane contactor for hydrogen sulphide absorption, J. Membr. Sci. 427 (2013) 276-282.

M.J.W. Frank, J.A.M Kuipers, W.P.M. Van Swaaij, Diffusion coefficients and viscosities of $\mathrm{CO}_{2}+\mathrm{H}_{2} \mathrm{O}$, $\mathrm{CO}_{2}+\mathrm{CH}_{3} \mathrm{OH}, \mathrm{NH}_{3}+\mathrm{H}_{2} \mathrm{O}$, and $\mathrm{NH}_{3}+\mathrm{CH}_{3} \mathrm{OH}$ liquid mixtures, J. Chem. Eng. Data 41 (1996) 297302.

A.C.M. Franken, J.A.M. Nolten, M.H.V. Mulder, D. Bargeman, C.A. Smolders, Wetting criteria for the applicability of membrane distillation, J. Membr. Sci. 33 (1987) 315-328.

E. Guillen-Burrieza, R. Thomas, B. Mansoor, D. Johnson, N. Hilal, H. Arafat, Effect of dry-out on the fouling of PVDF and PTFE membranes under conditions simulating intermittent seawater membrane distillation (SWMD), J. Membr. Sci. 438 (2013) 126-139.

S. Heile, S. Rosenberger, A. Parker, B. Jefferson, E.J. McAdam, Establishing the suitability of symmetric ultrathin wall polydimethylsiloxane hollow-fibre membrane contactors for enhanced CO2 separation during biogas upgrading, J. Membr. Sci. 452 (2014) 37-45.

H. Herzog, O. Falk-Pedersen, The kvaerner membrane contactor: lessons from a case study in how to reduce capture costs. In: Proceedings of the $5^{\text {th }}$ International Conference on Greenhouse Gas Control Technologies, Cairns, August 13-16, 2000.

G.L. Jadav, V.K. Aswal, H. Bhatt, J. C. Chaudhari, P. S. Singh, Influence of film thickness on the structure and properties of PDMS membrane, J. Membr. Sci. 415-416 (2012) 624-634.

K. Li, J. Kong, X. Tan, Design of hollow fibre membrane modules for soluble gas removal, Chem. Eng. Sci. 55 (2000) 5579-5588. 
C. Makhloufi, E. Lasseugette, J.C. Remigy, B. Belaissaoui, D. Roizard, E. Favre, Ammonia based $\mathrm{CO}_{2}$ capture process using hollow fiber membrane contactors, J. Membr. Sci. 455 (2014) 236-246.

M. Persson, O. Jonsson, A. Wellinger, Biogas upgrading to vehicle fuel standards and grid injection, IEA Bioenergy Task 37 (2007) 20-21.

A. Read, F. Hofmann, Does biogas scrub up? Materials recycling world, December (2011) 20-21. escape in carbon capture process using ammonia method, Chem. Eng. Res. Des. 91 (2013) $2775-2781$

A. Thornton, Application of ion exchange for ammonium removal from municipal wastewaters, PhD Thesis, Cranfield University, 2007.

R.V. Thurston, R. C., Russo, K. Emerson, Aqueous ammonia equilibrium - tabulation of percent unionised ammonia, United States Environmental Protection Agency, EPA-600 3 (1979) 091.

R. Wang, D.F. Li, D.T. Liang, Modeling of $\mathrm{CO}_{2}$ capture by three typical amine solutions in hollow fiber membrane contactors, Chem. Eng. Process. 43 (2004) 849-856.

P.K. Weissenborn, R.J. Pugh, Surface tension and bubble coalescence phenomena of aqueous solutions of electrolytes, Langmuir, 11 (1995) 1422-1426.

Q. Zeng, Y. Guo, Z. Niu, W. Lin, Mass transfer coefficients for $\mathrm{CO}_{2}$ absorption into aqueous ammonia solution using a packed column, Ind. Eng. Chem. Res. 50 (2011) 10168-10175.

Q. Zeng, Y., Guo, Z. Niu, W. Lin, The absorption rate of $\mathrm{CO}_{2}$ by aqueous ammonia in a packed column, Fuel Process. Technol. 108 (2013) 76-81.

X. Zhang, P. Zhang, K. Wei, Y. Wang, R. Ma, The study of continuous membrane crystallisation on lysozyme. Desalination 219 (2008) 101-117.

H. Zhu, H. Wang, F. Wang, Y. Guo, H. Zhang, J. Chen, Preparation and properties of PTFE hollow fiber membranes for desalination through vacuum membrane distillation, J. Membr. Sci. 446 

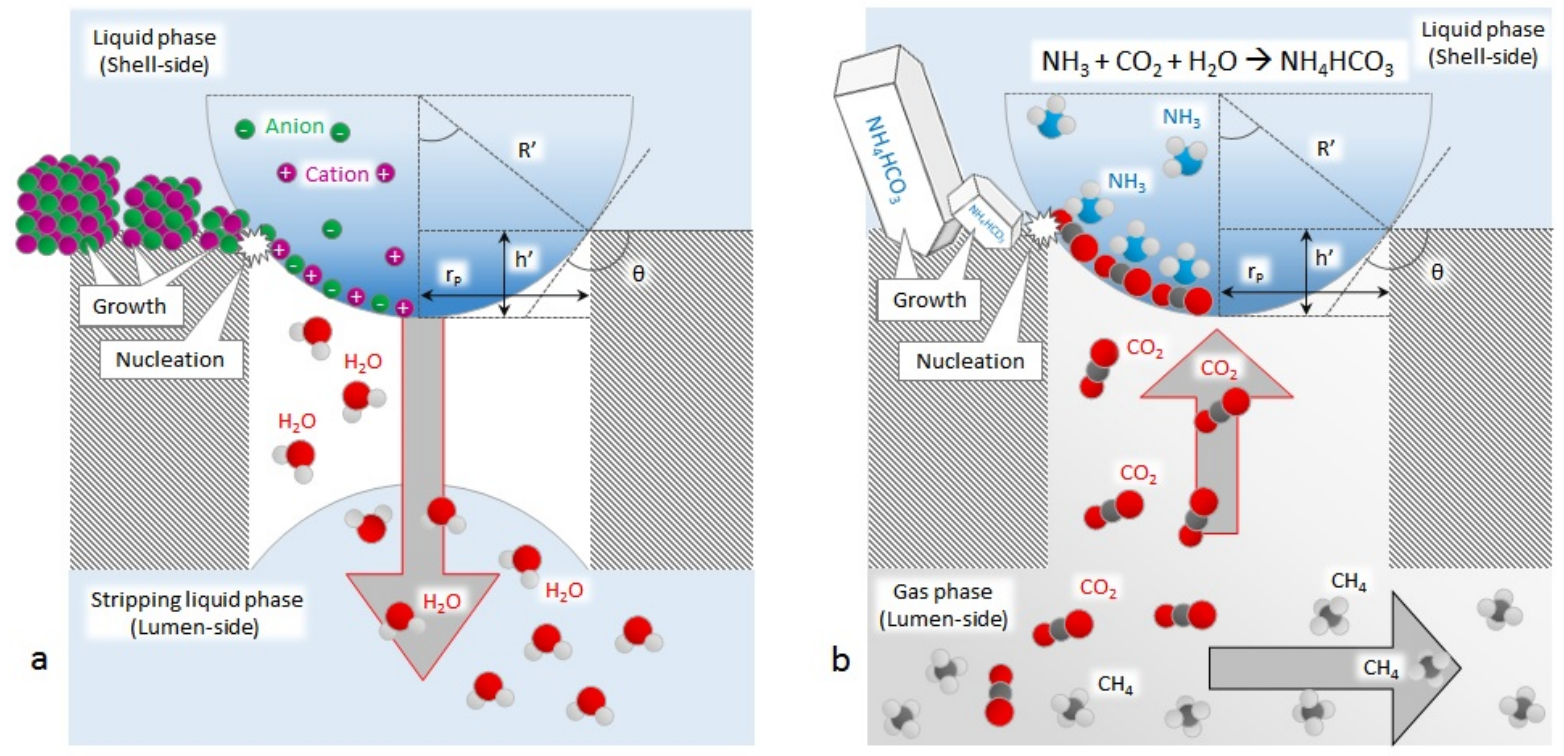

Figure 1. Mechanisms of crystallisation introduced: (a) membrane crystallisers typically achieve supersaturation through removing solvent (often water) as vapour to induce heterogeneous nucleation; and (b) the proposed gas-liquid membrane crystalliser where $\mathrm{CO}_{2}$ absorbed within an $\mathrm{NH}_{3}$ rich solution induces supersaturation through continuous $\mathrm{CO}_{2}$ flux from the gas phase leading to nucleation of an $\mathrm{NH}_{4} \mathrm{HCO}_{3}$ product.

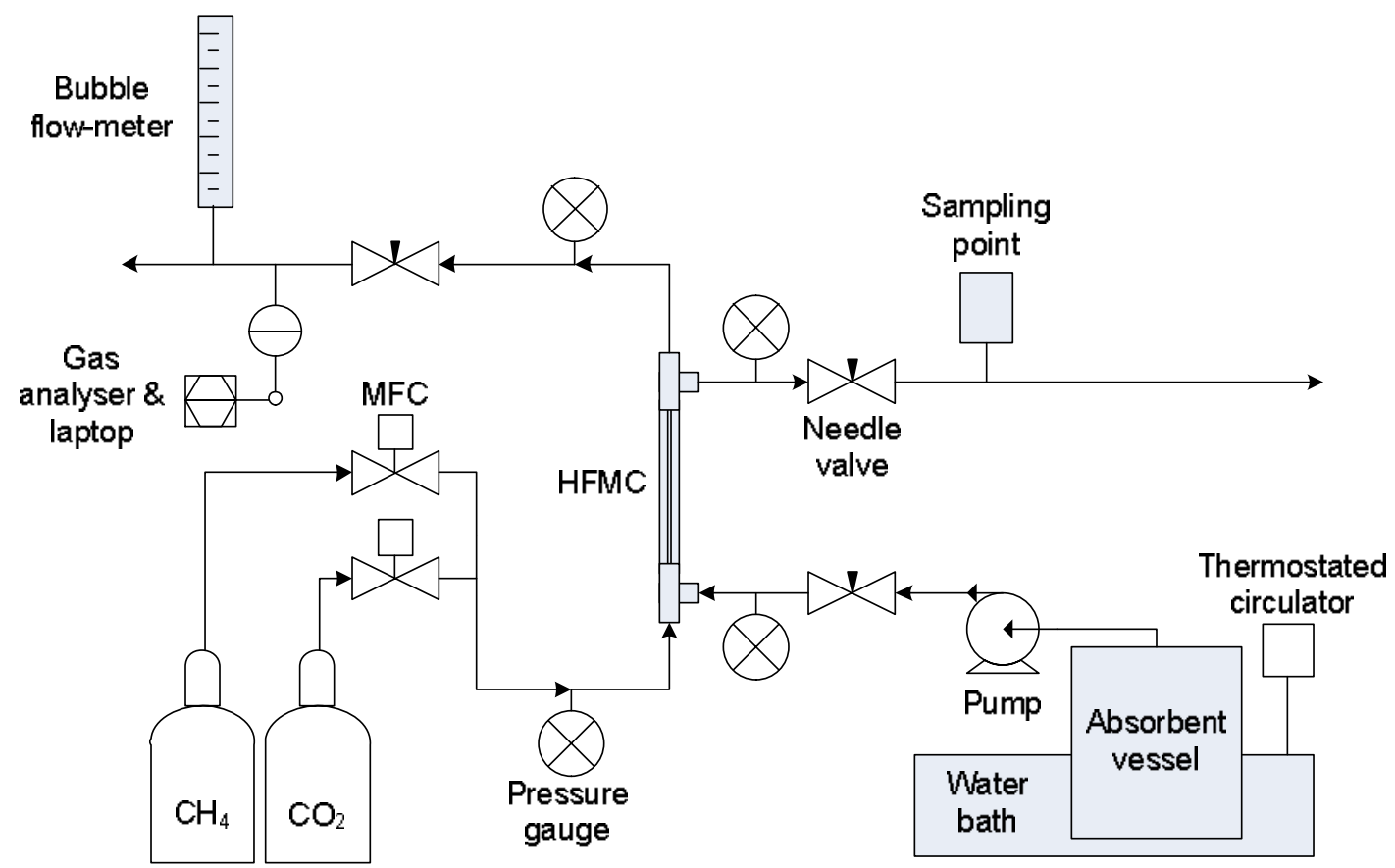

Figure 2. Schematic of experimental apparatus. 


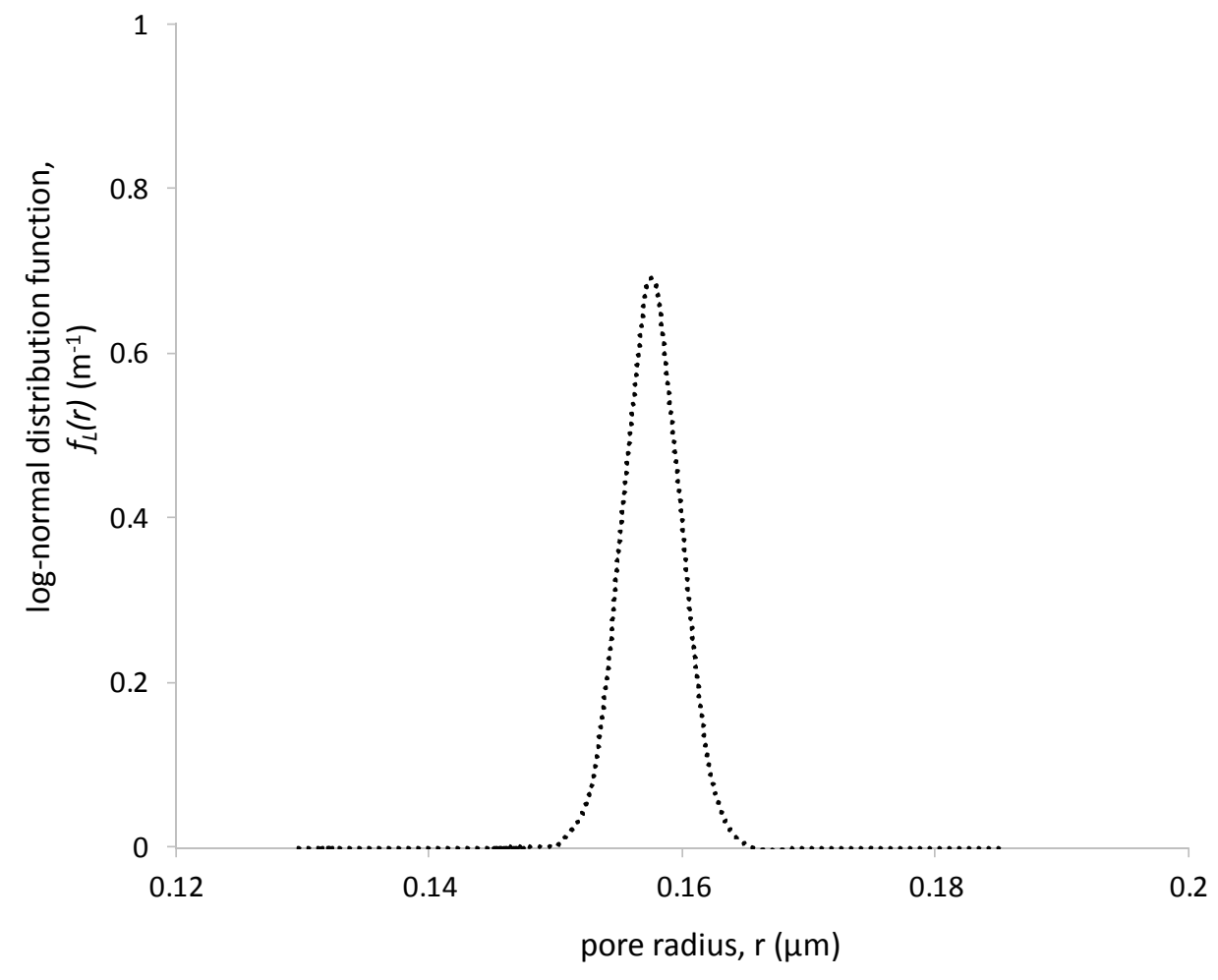

Figure 3. Statistical determination of pore radii using log-normal distribution.

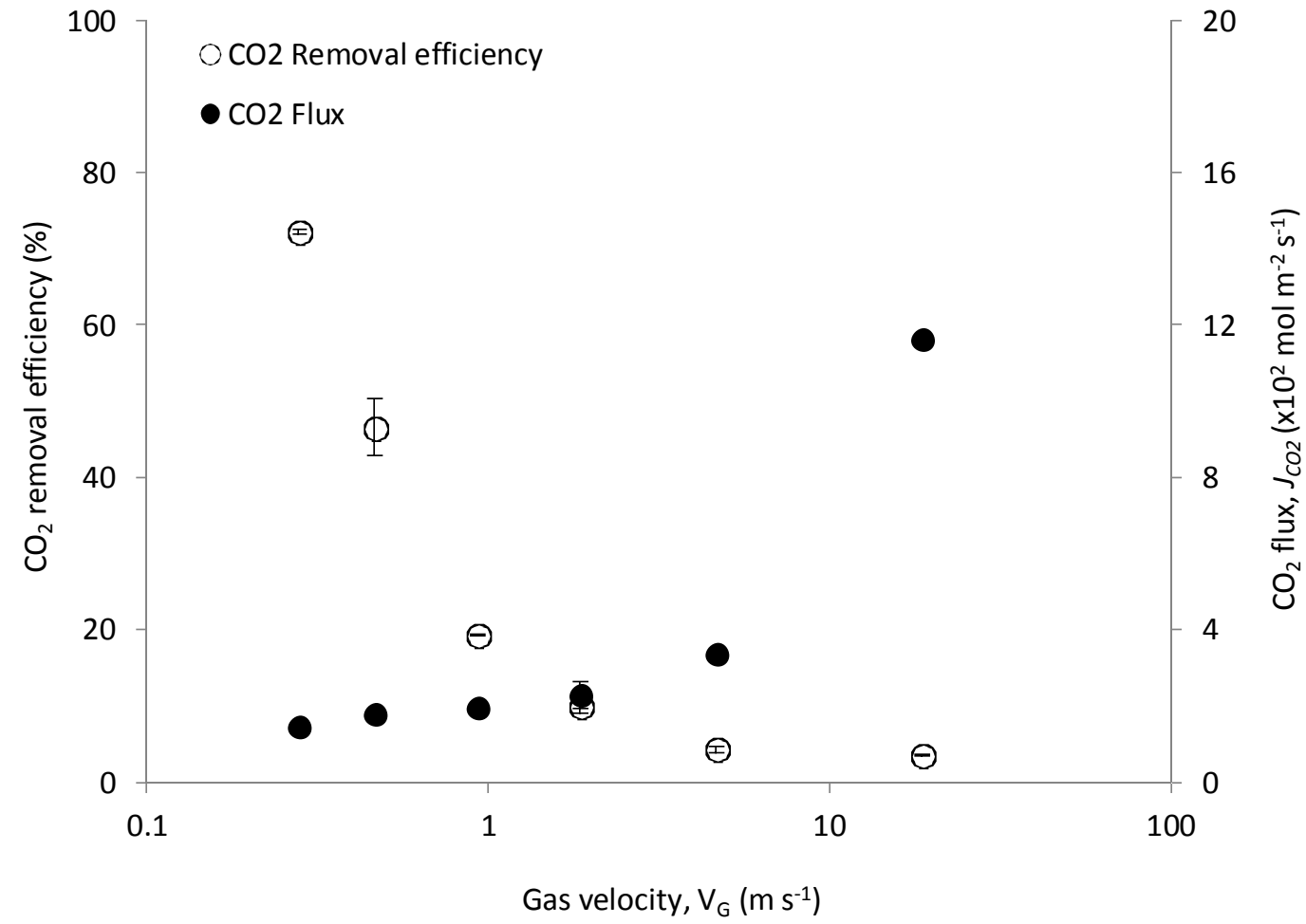

Figure 4. Effect of variable gas velocity $\left(\mathrm{V}_{\mathrm{G}}\right)$ upon $\mathrm{CO}_{2}$ removal efficiency; and $\mathrm{CO}_{2}$ flux, during absorption from a 50:50 $\mathrm{CO}_{2}: \mathrm{CH}_{4}$ gas mixture using $7 \mathrm{~mol} \mathrm{I}^{-1}$ aqueous ammonia solution at fixed liquid velocity $\left(\mathrm{V}_{\mathrm{L}}, 0.02 \mathrm{~m} \mathrm{~s}^{-1}\right)$ in a single fibre PTFE HFMC. Error bars indicate standard error. 


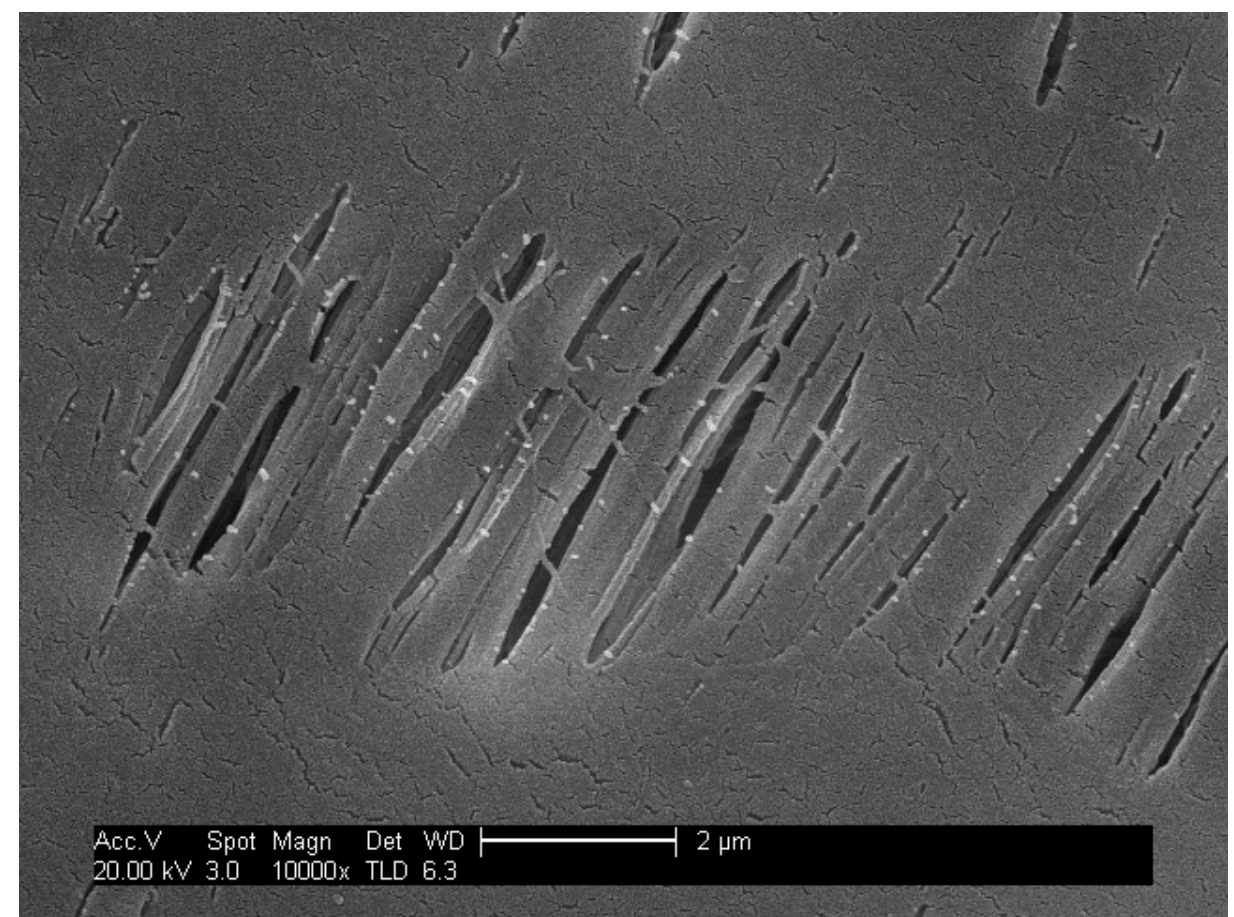

Figure 5. SEM surface analysis of $\mathrm{NH}_{4} \mathrm{HCO}_{3}$ crystal nucleation at the membrane-absorbent interface (shell-side) following $\mathrm{CO}_{2}$ absorption using a $7 \mathrm{~mol} \mathrm{I}^{-1} \mathrm{NH}_{3}$ solution in single pass operation ( $\left.\mathrm{x} 10000\right)$.

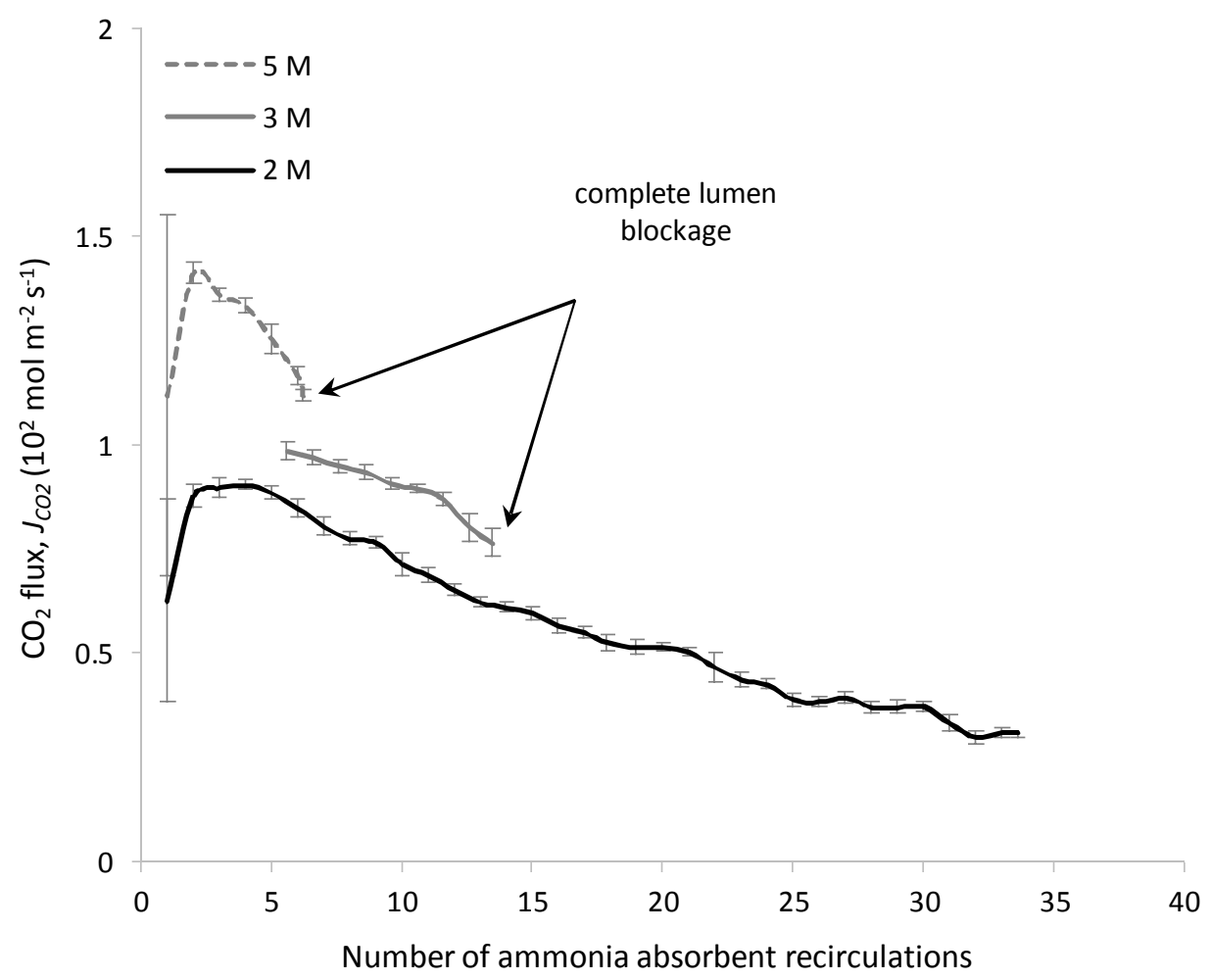

Figure 6. Carbon dioxide flux observed with the PTFE membrane following ammonia absorbent recirculation ( $2 \mathrm{M}, 3 \mathrm{M}$ and $5 \mathrm{M}$ ) through the shell-side of the module. Hydrodynamic conditions: $\mathrm{G} / \mathrm{L} 10 ; V_{\mathrm{G}} 0.93 \mathrm{~m} \mathrm{~s}^{-1} ; \mathrm{V}_{\mathrm{L}} 0.02 \mathrm{~m} \mathrm{~s}^{-1}$. Lumen side blockage observed for $3 \mathrm{M}$ and $5 \mathrm{M}$ solutions. Error bars indicate standard error. 


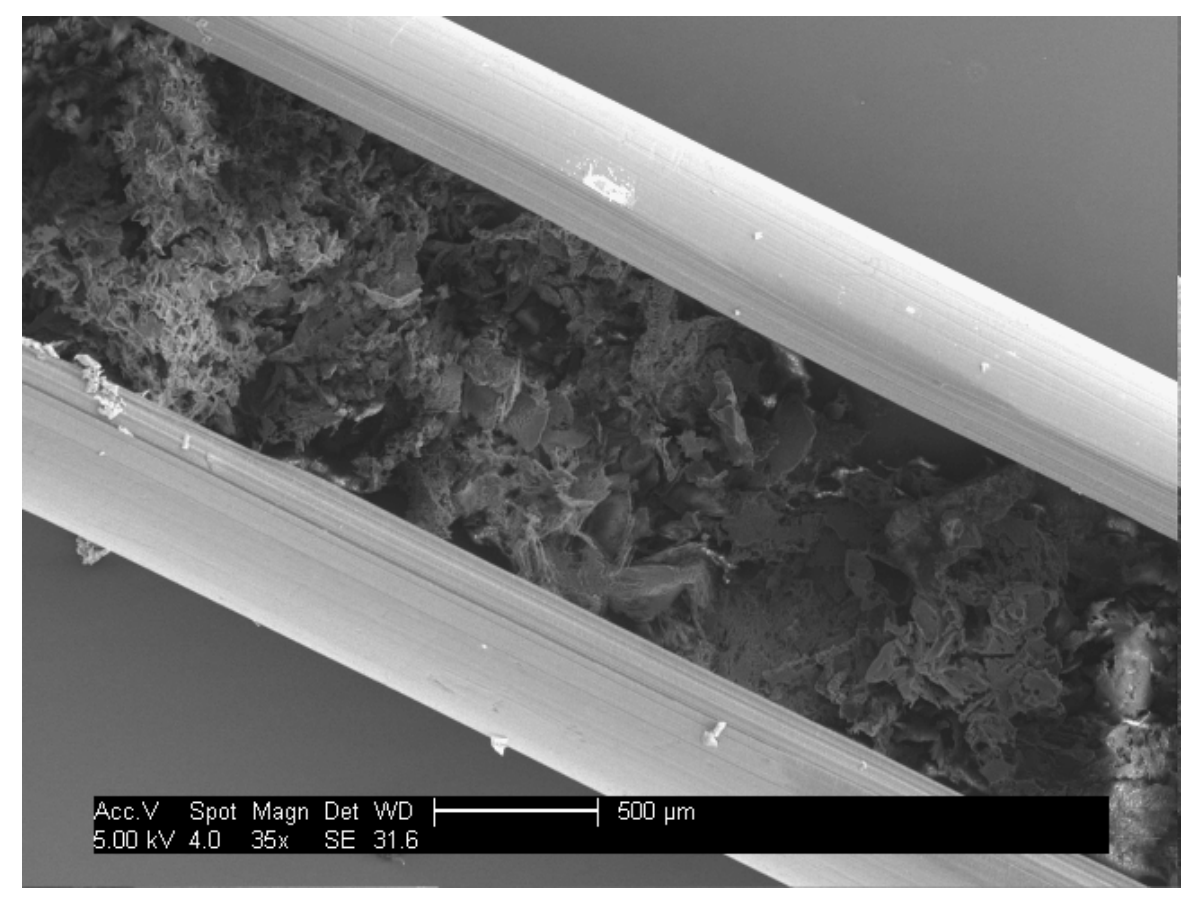

Figure 7. Dissected section of the micro-porous PTFE hollow fibre membrane used for $5 \mathrm{M} \mathrm{NH}$ absorbent recirculation. The experiment was stopped after 6 recirculations due to gas-side (lumen side) blockage. SEM analysis demonstrates fibre blockage due to formation of $\mathrm{NH}_{4} \mathrm{HCO}_{3}$ crystals. Hydrodynamic conditions: $\mathrm{G} / \mathrm{L} 10 ; \mathrm{V}_{\mathrm{G}} 0.93 \mathrm{~m} \mathrm{~s}^{-1} ; \mathrm{V}_{\mathrm{L}} 0.02 \mathrm{~m} \mathrm{~s}^{-1}$.

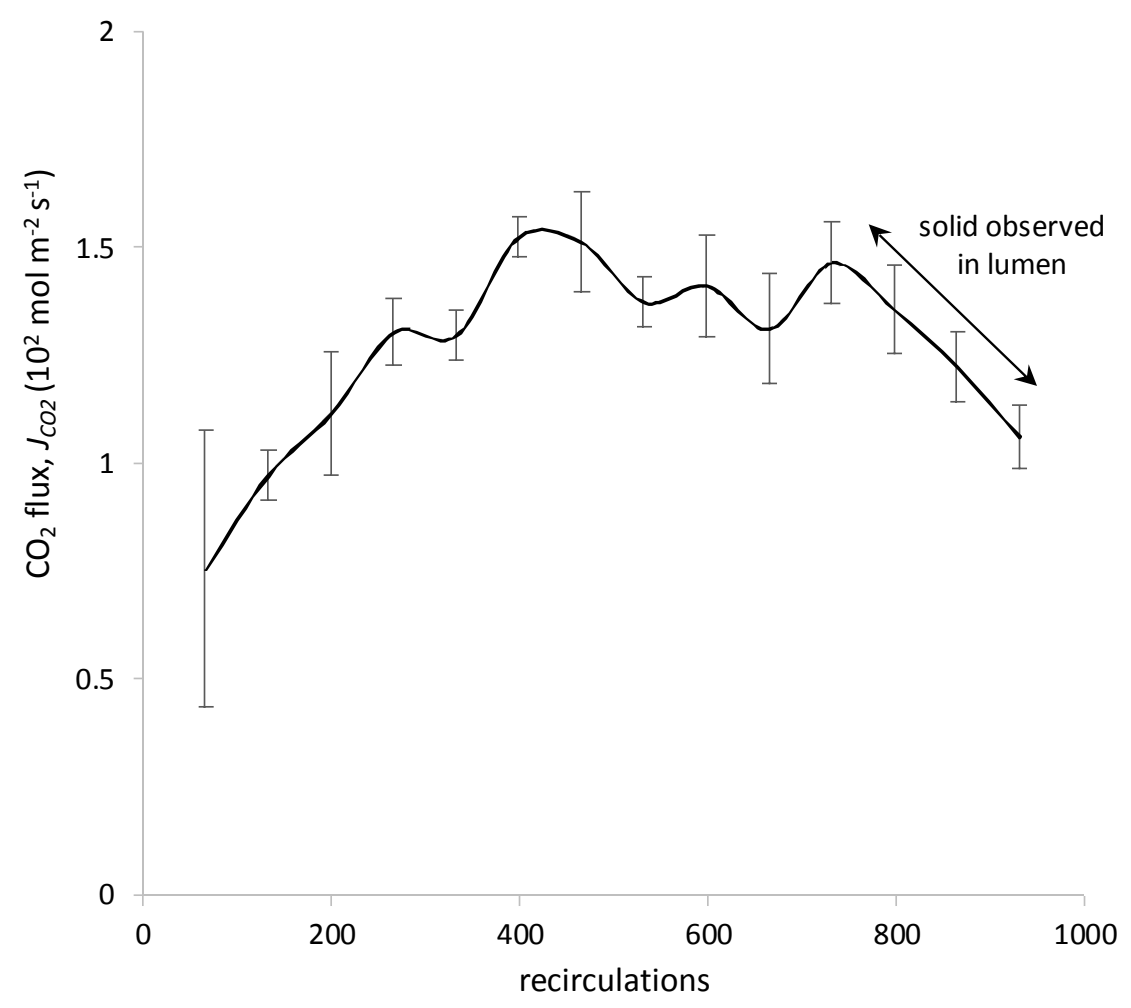

Figure 8. Carbon dioxide flux observed with the nonporous PDMS hollow fibre membrane using 5M $\mathrm{NH}_{3}$ absorbent recirculated through the module shell-side. Gas-side (lumen side) blockage noted following 800 solvent recirculations. Hydrodynamic conditions: $\mathrm{G} / \mathrm{L} 0.4 ; \mathrm{V}_{\mathrm{L}} 0.1 \mathrm{~m} \mathrm{~s}^{-1}$. Error bars indicate standard error. 


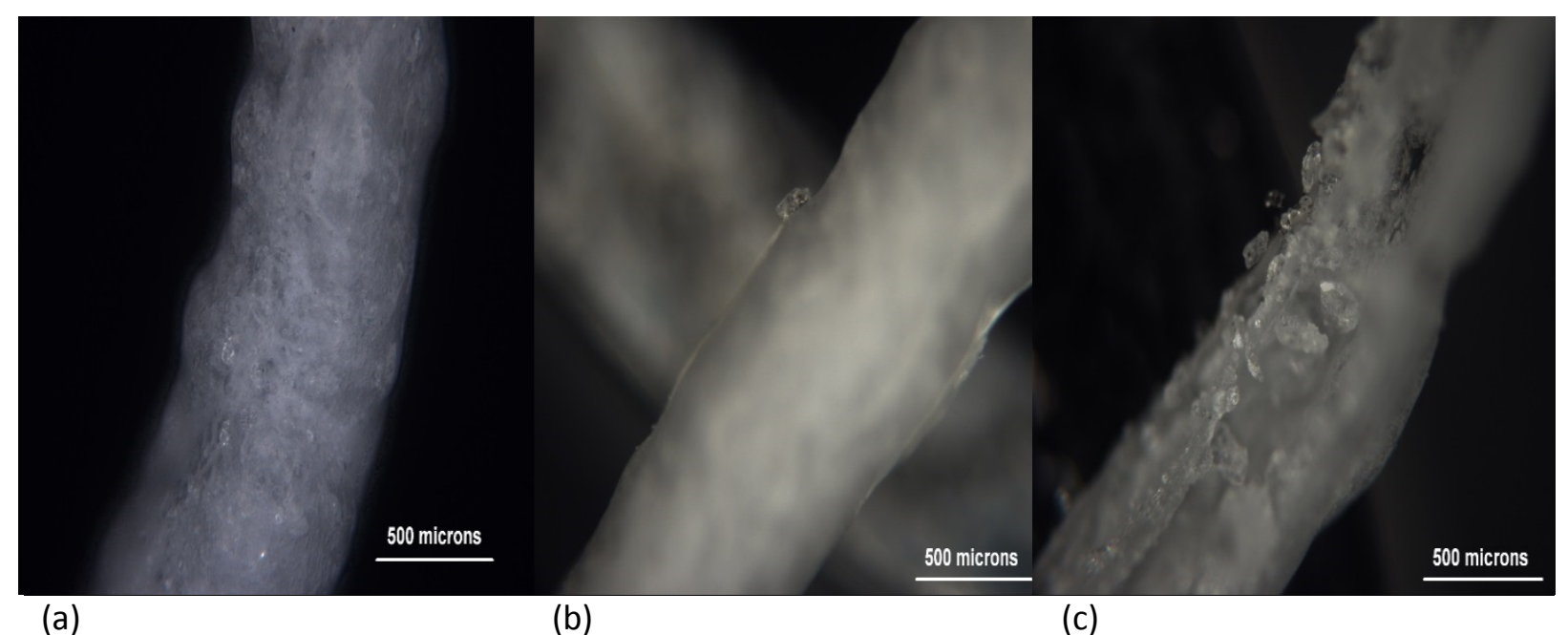

(a)

(b)

(c)

Figure 9. Nonporous PDMS hollow fibre membrane following $>800$ recirculations of $5 \mathrm{M} \mathrm{NH_{3 }}$ absorbent: (a) crystals formed inside the fibre lumen; (b) an example crystal formed on the outside of the fibre; and (c) the PDMS fibre dissected reveals crystals formed within the fibre lumen.

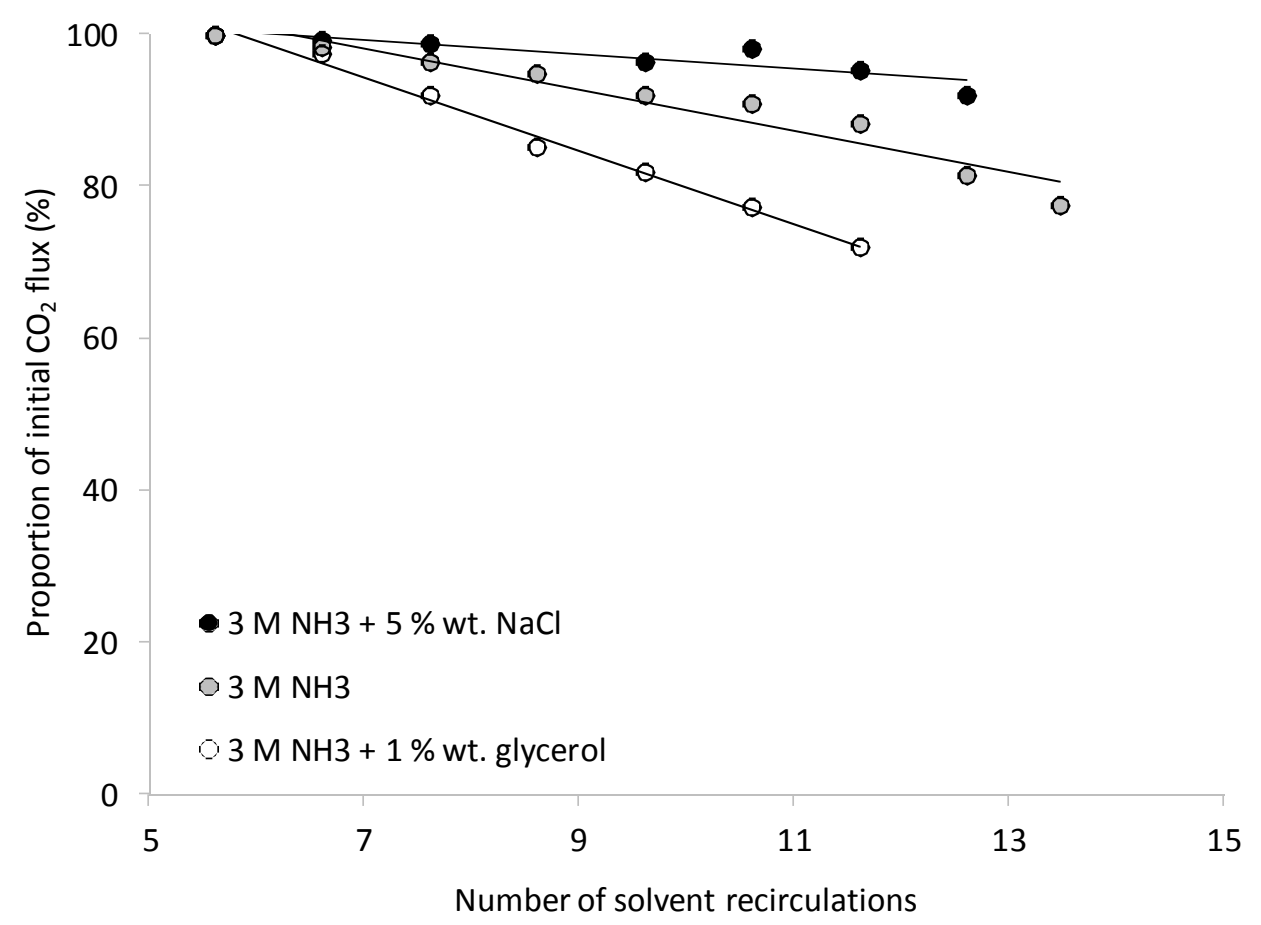

Figure 10. Impact of sodium chloride $(5 \% \mathrm{NaCl})$ and glycerol $\left(1 \% \mathrm{C}_{3} \mathrm{H}_{8} \mathrm{O}_{3}\right)$ on $\mathrm{CO}_{2}$ flux when used as additives to $3 \mathrm{M} \mathrm{NH}$ absorbent recirculated through the module shell-side. Hydrodynamic conditions: $\mathrm{G} / \mathrm{L} 10 ; \mathrm{V}_{\mathrm{G}} 0.93 \mathrm{~m} \mathrm{~s}^{-1} ; \mathrm{V}_{\mathrm{L}} 0.02 \mathrm{~m} \mathrm{~s}^{-1}$. 


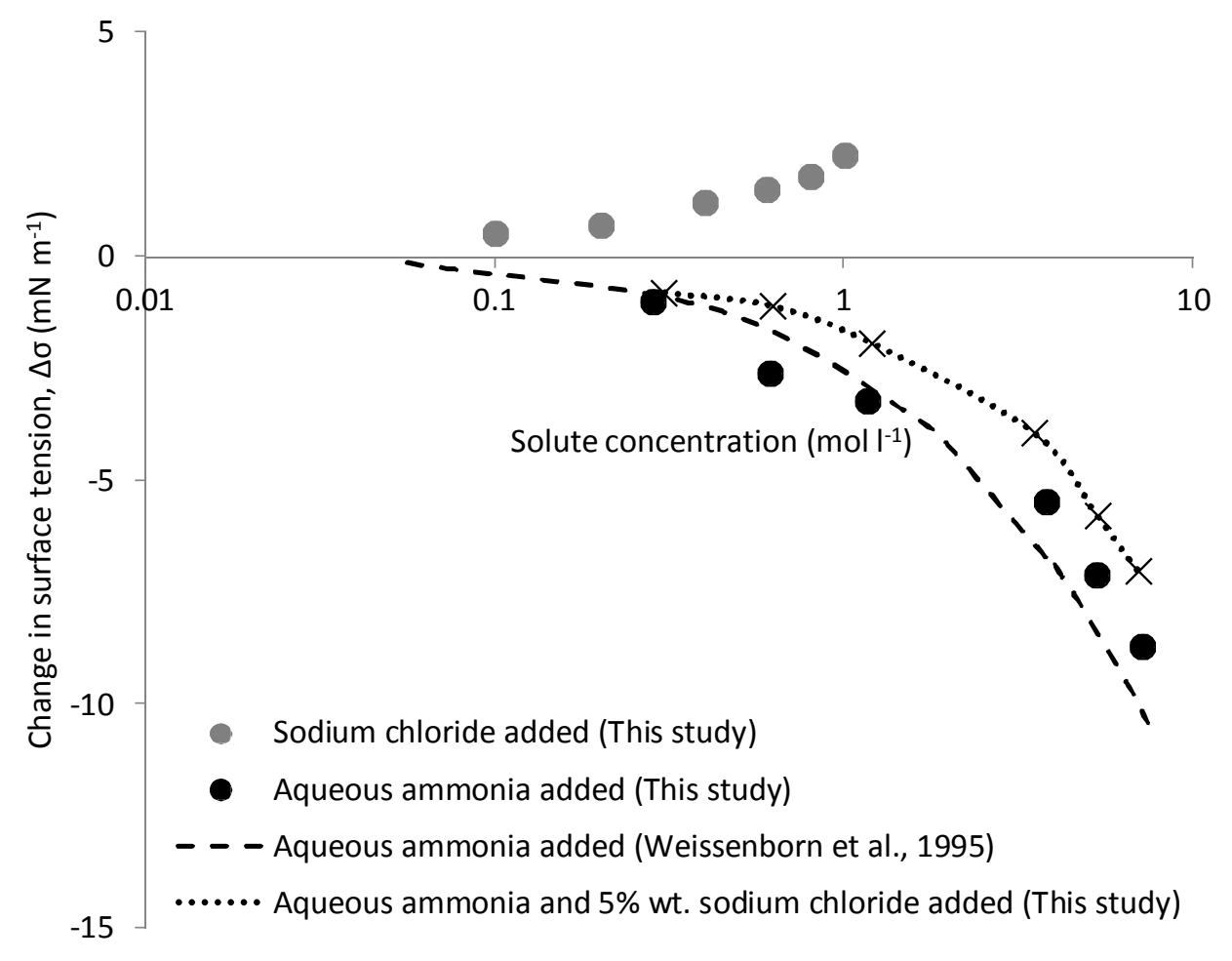

Figure 11. Changes in surface tension relative to deionised water driven by aqueous ammonia and sodium chloride solute concentration within the concentration range examined $\left(\mathrm{NH}_{3}, 2-7 \mathrm{M} ; \mathrm{NaCl} 5 \%\right.$ wt. or 0.85 M) (Weissenborn et al., 1995).

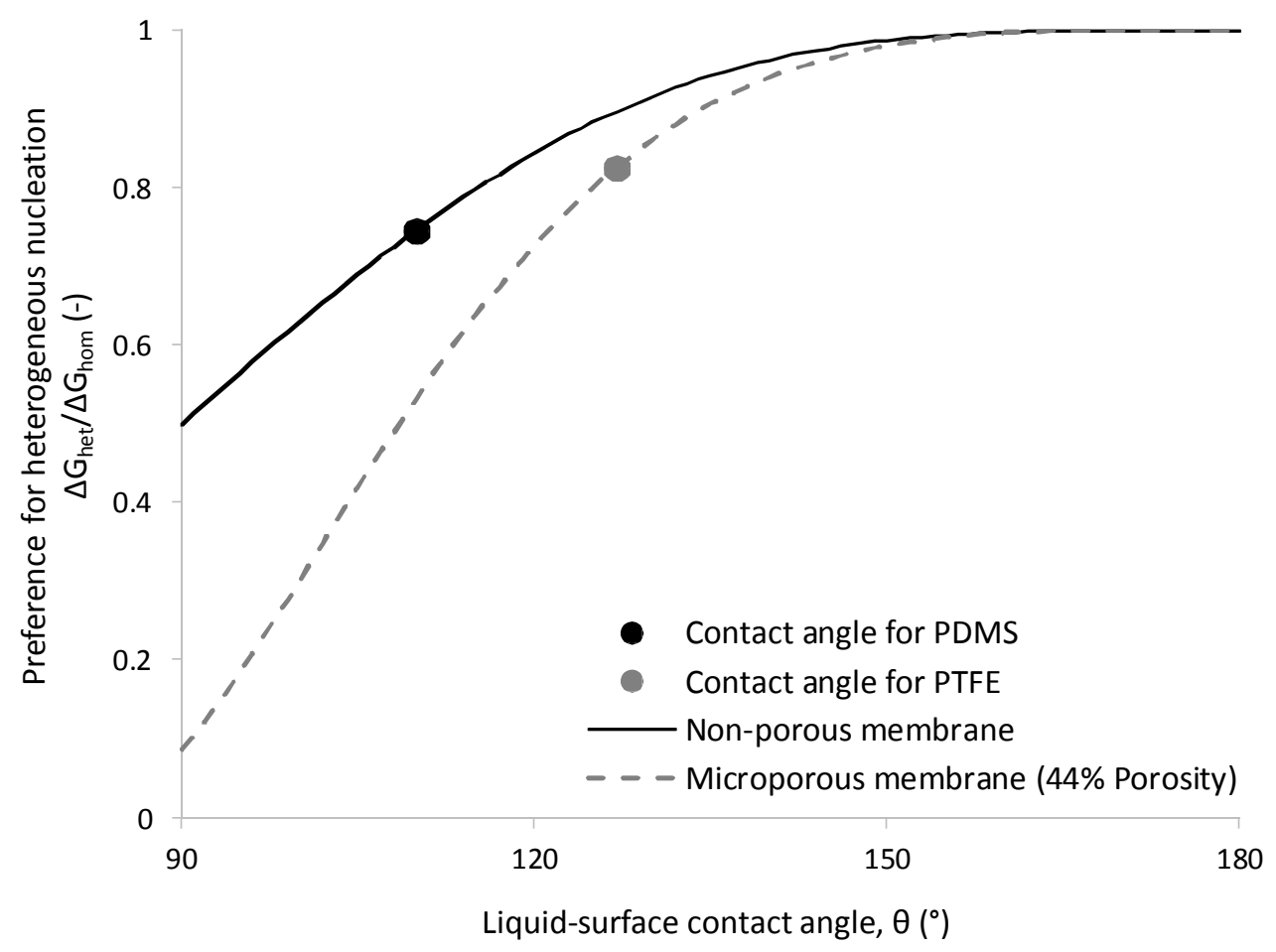


Figure 12. Impact of liquid-surface contact angle on the thermodynamic favourability of heterogeneous vs. homogeneous nucleation calculated for the non-porous PDMS membrane and PTFE micro-porous membrane used (Appendix, Eq. A1).

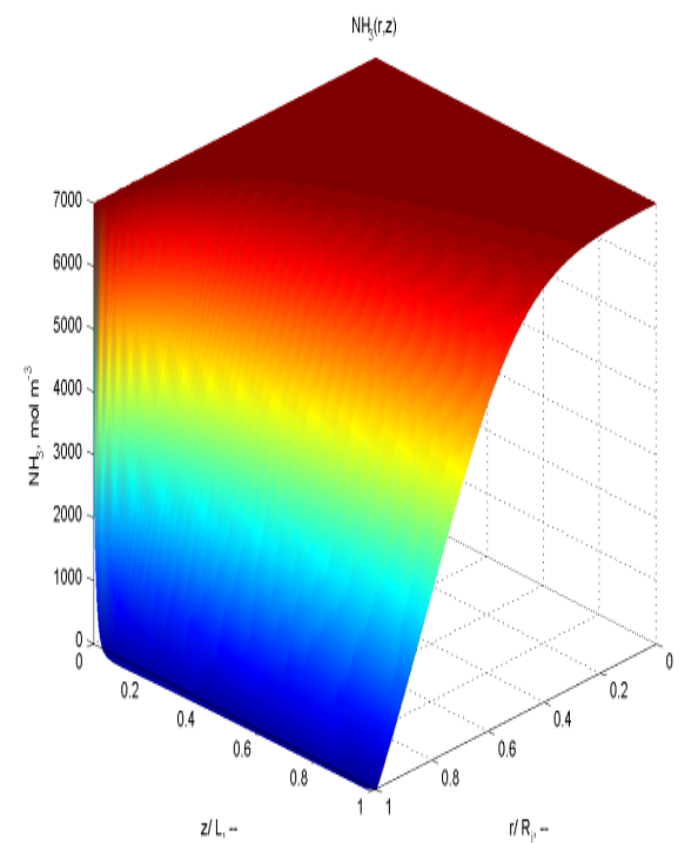

(a)

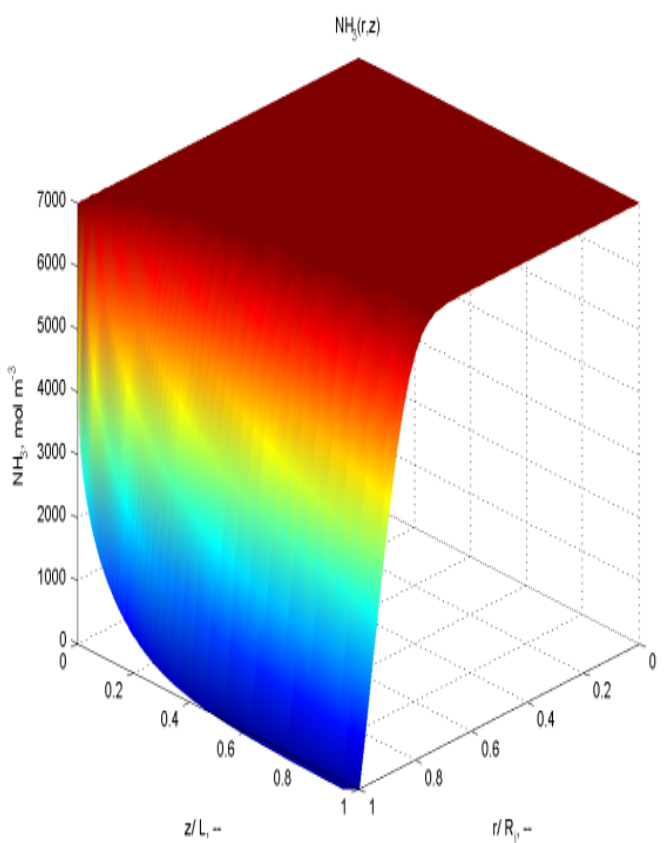

(b)

Figure 13. An illustration of $\mathrm{NH}_{3}$ depletion by chemical reaction with $\mathrm{CO}_{2}$ : (a) extending into the liquid bulk at low $\mathrm{V}_{\mathrm{L}}$; and (b) confined to the liquid boundary layer at high $\mathrm{V}_{\mathrm{L}}$. For supporting calculations, see Appendix.

Table 1. Dimensions and surface characteristics of the single membrane fibres

\begin{tabular}{|c|c|c|c|}
\hline & & PDMS $^{b}$ & PTFE $^{b}$ \\
\hline \multicolumn{4}{|l|}{ Fibre characteristics } \\
\hline Inner diameter & $\mathrm{mm}$ & 0.18 & 1.51 \\
\hline Outer diameter & $\mathrm{mm}$ & 0.31 & 1.91 \\
\hline Wall thickness & $\mu \mathrm{m}$ & 65 & 200 \\
\hline Active length & $\mathrm{m}$ & 0.1 & 0.1 \\
\hline Surface area $^{a}$ & $\mathrm{~m}^{2}$ & $0.97 \times 10^{-4}$ & $6 \times 10^{-4}$ \\
\hline Porosity & $\%$ & - & 44 \\
\hline Mean pore radius & $\mu \mathrm{m}$ & - & 0.16 \\
\hline Average surface roughness ${ }^{c}$ & $\mathrm{~nm}$ & 76.6 & 82.2 \\
\hline Lumen cross sectional area & $\mathrm{m}^{2}$ & $2.54 \times 10^{-8}$ & $1.79 \times 10^{-6}$ \\
\hline \multicolumn{4}{|l|}{ Shell-side characteristics } \\
\hline Inner diameter & $\mathrm{mm}$ & 6 & 6 \\
\hline Outer diameter & $\mathrm{mm}$ & 4 & 4 \\
\hline Shell cross sectional area & $\mathrm{m}^{2}$ & $2.82 \times 10-5$ & $2.54 \times 10-5$ \\
\hline Priming volume & $\mathrm{ml}$ & 2.82 & 2.54 \\
\hline \multicolumn{4}{|c|}{ Operational Characteristics } \\
\hline Flow regime & & Co-current & Co-current \\
\hline Shell-side & & $5 \mathrm{M} \mathrm{NH}_{3}$ (aq.) & $2,3,5,7 \mathrm{M} \mathrm{NH}_{3}$ (aq.) \\
\hline Lumen-side & & $50: 50 \mathrm{CO}_{2}: \mathrm{CH}_{4}$ & $50: 50 \mathrm{CO}_{2}: \mathrm{CH}_{4}$ \\
\hline
\end{tabular}

${ }^{a}$ Based on fibre outer diameter. ${ }^{b}$ Data provided by manufacturer. ${ }^{c}$ Measured using AFM. 
Table 2. SEM images and EDX analyses of ammonium bicarbonate crystals grown on the PTFE membrane at the membrane-absorbent interface (shell-side) during recirculation of aqueous ammonia absorbents ranging 2 to $5 \mathrm{~mol}^{-1}$ in concentration.

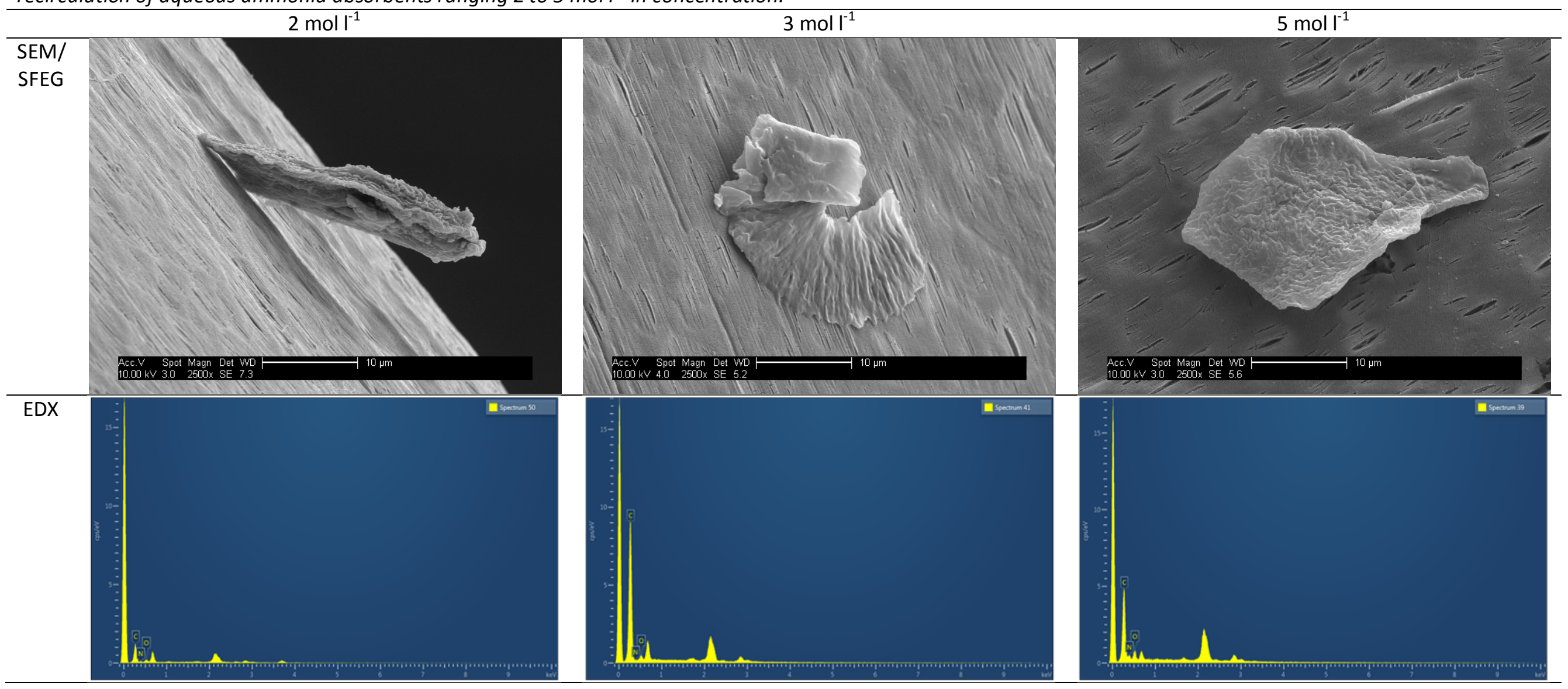


Table B1. Parameters determined for modelling of $\mathrm{CO}_{2}$ absorption in $\mathrm{NH}_{3}$ solutions of concentrations relevant to the present study adjusted for a system at $25{ }^{\circ} \mathrm{C}$

\begin{tabular}{|c|c|c|c|c|c|c|c|c|c|c|c|c|c|}
\hline $\begin{array}{c}\mathrm{C}_{\mathrm{NH3}} \\
\mathrm{kmol} \mathrm{m}^{-3}\end{array}$ & $\begin{array}{c}\mathrm{X}_{\mathrm{NH3}} \\
(-)\end{array}$ & $\begin{array}{l}\eta^{\mathrm{NH3} \text { (aq.) }} \\
10^{4} \mathrm{~Pa} \mathrm{~s}\end{array}$ & $\begin{array}{l}D_{C O 2}^{N H 3(a q .)} \\
10^{9} \mathrm{~m}^{2} \mathrm{~s}^{-1}\end{array}$ & $\begin{array}{l}D_{N H 3}^{N H 3(a q .)} \\
10^{9} \mathrm{~m}^{2} \mathrm{~s}^{-1}\end{array}$ & $\begin{array}{c}\eta^{\mathrm{H} 2 \mathrm{O}} \\
10^{4} \mathrm{~Pa} \mathrm{~s}\end{array}$ & $\begin{array}{c}\mathrm{m}_{\mathrm{CO} 2} \\
(-)\end{array}$ & $\begin{array}{c}D_{\mathrm{CO} 2}^{\mathrm{H} 2 \mathrm{O}} \\
10^{9} \mathrm{~m}^{2} \mathrm{~s}^{-1}\end{array}$ & $\begin{array}{c}\mathrm{k}_{2} \\
\mathrm{~m}^{3} \mathrm{~mol}^{-1} \mathrm{~s}^{-1}\end{array}$ & $\begin{array}{l}\mathrm{k}_{\mathrm{NH} 3} \mathrm{k}_{2} / \mathrm{k}_{-1} \\
\mathrm{~m}^{6} \mathrm{~mol}^{-2} \mathrm{~s}^{-1}\end{array}$ & $\begin{array}{c}\mathrm{k}_{\mathrm{H}_{2} \mathrm{O}_{2} / \mathrm{k}_{-1}} \\
\mathrm{~m}^{6} \mathrm{~mol}^{-2} \mathrm{~s}^{-1}\end{array}$ & $\begin{array}{c}A_{k 2} \\
10^{3} \mathrm{~K}^{-1}\end{array}$ & $\begin{array}{c}A_{k N H 3 k 2 / k-1} \\
10^{3} \mathrm{~K}^{-1}\end{array}$ & $\begin{array}{c}A_{k H 20 k 2 / k-1} \\
10^{3} K^{-1}\end{array}$ \\
\hline 2 & 0.038 & 9.61 & 1.80 & 2.11 & 8.84 & 0.83 & 1.92 & 7.5 & $3.8 \times 10^{-4}$ & $2.6 \times 10^{-6}$ & 3.0 & 8.5 & 5.5 \\
\hline 3 & 0.058 & 9.82 & 1.76 & 2.17 & " & “ & $"$ & " & $"$ & “ & " & $"$ & $"$ \\
\hline 5 & 0.102 & 10.29 & 1.70 & 2.31 & " & “ & “ & “ & “ & “ & “ & “ & $"$ \\
\hline 7 & 0.151 & 10.82 & 1.63 & 2.47 & $"$ & " & " & “ & “ & “ & " & “ & $"$ \\
\hline
\end{tabular}

